Journal of Environmental Science and Public Health

doi: $10.26502 /$ jesph.96120051

fortune

Volume 3, Issue 1

Research Proposal

\title{
Biodiesel Production from Allanblackia floribunda Seed oil
}

\author{
Sylvia Adipah*
}

Department of Environmental Engineering and Science, Chongqing University, Chongqing, China

*Corresponding Author: Sylvia Adipah, Department of Environmental Engineering and Science, Chongqing University, Chongqing, China, E-mail: $\underline{\text { ransil351@yahoo.com }}$

Received: 12 December 2018; Accepted: 03 January 2019; Published: 08 February 2019

\section{Introduction}

At present, one of the ongoing challenges facing human society is to continue to provide energy in usable forms such as electricity while there is a growth in population and global warming are increasing. Under these circumstances, the utilization of renewable energy resources has become a global strategy for sustainable energy use, which is of particular importance for coping with increasing stress from the energy crises and global warming. Biogas has been developed rapidly and globally as an effective method to generated renewable energy, energy production and sustains environmental production.

\subsection{Biodiesel}

Biodiesel is defined as an oxygenated, sulfur-free, biodegradable, non-toxic, and eco-friendly alternative diesel oil. It can be derived from renewable sources, such as vegetable oil, animal fat, and used cooking oil that meets the requirements of ASTM and European standards. These renewable sources are composed of mono-alkyl esters of long chain fatty acids. Biofuel must meet the stringent quality standards to be considered as viable transportation fuel. One of the methods of producing biodiesel is transesterification. As a result of high viscosity, there is the need of injection and atomization characteristics of vegetable oil compared to those obtained petroleum diesel fuels. To improve the performance of most modern diesel engines those have fuel injection system sensitive to viscosity change, one way to avoid this problem is to reduce fuel viscosity of vegetable oil. Another effective way is by converting vegetable oil into biodiesel such as dilution, micro emulsification, pyrolysis, and transesterification are the four techniques used to solve the problems encountered with the high fuel viscosity. 
The most common methods use is tranesterification leading to mono alkyl esters of vegetable oils and fats, now called biodiesel when used for fuel purposes. The methyl ester produced by transesterification of vegetable oil has a high cetane number, low viscosity and improved heating value compared to those of pure vegetable oil which results in shorter ignition delay and longer combustion duration and hence low particulate emissions.

\section{Research Questions}

- How will the technology help to generate sustainable energy?

- Is biogas production from Allanblackia floribunda Seed oil environmentally friendly?

- How do we improve the efficiency of the biogas production from Allanblackia floribunda Seed oil?

- Is biogas production from Allanblackia floribunda Seed oil cost-effective compared to other technologies?

\section{Aim/Objective of the Research}

The main objective of this study is to investigate the feasibility of using Allanblackia floribunda Seed oil as a new potential non-edible feedstock for biodiesel production. The specific objectives of the study include;

i. To synthesize four novel dicationic functional ionic liquids with an imidazolium structure for biodiesel production

ii. To investigate the catalytic performance of transesterification of Allanblackia floribunda Seed oil with methanol to biodiesel

iii. To determine the effect of the optimization of reaction conditions on the transesterification using the response surface methodology (RSM)

iv. To evaluate the properties and application feasibility of the biodiesel obtained from Allanblackia floribunda Seed oil

v. To use biogas production from Allanblackia floribunda Seed oil as an effective method to generate renewable energy.

\section{Significant of the Research}

With the shortening and increasing scarcity of known petroleum reserves which has made renewable energy sources more attractive and significant, the outcome of this study is to sell out Allanblackia floribunda Seed oil and promote it cultivation. The study will also draw focus to other non-edible oil for biodiesel production. The study is also believed to bring enhancement and reduction of greenhouse gas emissions, regional development and social structure, especially to developing countries. The study is also fore saw to bring a balance between agriculture, economic development, and the environment. It is also expected that the methyl esters will help improve the lubrication properties of diesel fuel blend which will subsequently help reduce long term engine wear in diesel engines since biodiesel is said to be a good lubricant (about $66 \%$ better than petrodiesel). 


\section{Outcome of the Research}

Is to use Allanblackia floribunda Seed oil to produce biogas energy with increasing stress from the energy crises.

\section{Expected Results}

The study is expected to cover the process of Allanblackia floribunda Seed oil biodiesel production including synthesis of the catalyst, monitoring of the biodiesel production, the most enhanced method for the production of biodiesel and the efficient method for the biodiesel purification using. It is expected that the result of these studies will create the awareness and consequently enhance the cultivation and comprehensive use of Allanblackia floribunda Seed oil. The study is expected to contribute knowledge to the scientific world. It is also expected that at least two or more publications will be obtained from the studies.

\section{Materials}

Crude Allanblackia floribunda Seed oil, Methanol, acetone, dichloromethane, N-methyl imidazole, acetonitrile, ethyl acetate, $\mathrm{NaOH}, 1$, 2-dibromoethane, 1, 3-dibromopropane, 1, 4-dibromobutane, 1, 5-dibromopentane, and 1, 6dibromohexane will be used (grade of analytical reagent). Preparation of dicationic ionic liquids.

\subsection{Preparation of intermediates of $[\mathrm{m} I \mathrm{~m}] 2 \mathrm{CnBr} 2$}

Mixture of 1, 2-dibromoethane $(0.02 \mathrm{~mol}, 3.75 \mathrm{~g})$ and dehydrated $\mathrm{N}$-methyl-imidazole $(0.04 \mathrm{~mol}, 3.284 \mathrm{~g})$ will be stirred with $50 \mathrm{~mL}$ acetonitrile solution in a three-neck flask at $70^{\circ} \mathrm{C}$ for $24 \mathrm{hrs}$. The mixture will be cooled to room temperature and filtered to give a crude solid. The crude solid will then be washed a number of times (3) with acetone and then vacuum-dried. By the same method, bis-(3-methyl-1-imidazole) -propylene dibromo-salt, bis-(3methyl-1-imidazole)-butylene dibromo-salt, bis-(3-methyl-1-imidazole)-pentylene dibromosalt, and bis-(3-methyl-1imidazole)-hexylene dibromic salt will be synthesized.

\subsection{Preparation of dicationic functional ionic liquids}

Bis-(3-methyl-1-imidazole)-ethylene dibromosalt $(0.01 \mathrm{~mol}, 3.52 \mathrm{~g})$ and $\mathrm{NaOH}(0.02 \mathrm{~mol}, 0.8 \mathrm{~g})$ will be dissolved with $50 \mathrm{~mL}$ acetone solvent in a single-neck flask and stirred at room temperature for a day. The resulting precipitate of sodium bromide will be removed through filtration with the solvent allowed to evaporate under vacuum. The mixture will be washed repeatedly with dichloromethane, then evaporated under reduced pressure to yield the product (pale yellow powder bis-(3-methyl-1-imidazole)-ethylene dihydroxide,) expressed as IMC2OH. Via the same procedure, bis-(3-methyl-1-imidazole)-propylene dihydroxide, bis-(3-methyl-1-imidazole)-butylene dihydroxide, bis-(3-methyl-1-imidazole)-pentylene dihydroxide, and bis-(3-methyl-1-imidazole)-hexylene dihydroxide will be prepared (IMC3OH, IMC4OH, IMC5OH, and IMC6OH, respectively).

\subsection{Transesterification of Crude Allanblackia floribunda Seed Oil}

The crude Allanblackia floribunda Seed oil will be dehydrated at $140^{\circ} \mathrm{C}$ under vacuum in the rotary evaporator for 2 hrs. The dehydrated crude Allanblackia floribunda Seed oil with a specified amount of dicationic functional ionic 
liquid catalyst will be mixed with excess methanol to form a homogenous reaction system in $100 \mathrm{~mL}$ three-neck flask and refluxed for some time at a recommended temperature under stirring with a constant speed. The ionic liquid catalyst will be available in the lower liquid phase. Mixture of methanol and glycerol will then be separated from the lower oily liquid phase by decantation. After draining off the glycerol, the upper mixture will be washed twice or more with 1:1 volume of water to remove excess methanol to achieve the target product.

\subsection{Alkali-catalyzed transesterification}

Methyl esters of Allanblackia floribunda Seed oil will be prepared by refluxing the oil at a preset temperature with a certain volume of methanol containing the catalyst for $2 \mathrm{hrs}$ in a $250 \mathrm{~mL}$ three-neck reaction flask equipped with a condenser. After the reaction, the product will be purified by neutralizing with $10 \%$ of sulphuric acid. The product will then be washed and dried under reduced pressure at a temperature of about $70^{\circ} \mathrm{C}$ with a rotary evaporator.

\section{Product Analyses and Yield Determination}

The methyl esters will be determined with GC-MS. This will be carried out on an Agilent HP-6890 gas chromatograph (Agilent Technologies, Palo Alto, CA, USA) with a HP-5MS 5\% phenylmethylsiloxane capillary column ( $30 \mathrm{~m} \times 0.25 \mathrm{~mm}$ i.d., film thickness $0.25 \mu \mathrm{m}$; Restek, Bellefonte, PA). The identification of fatty acids will be performed by comparing the obtained mass spectra with NIST05.LIB and NIST05s. LIB (National Institute of Standards and Technology) libraries data provided by the software (AMDIS-Chromatogram) of GC-MS system. Biodiesel yields will be determined with 7890 A gas chromatograph (Agilent Technology Inc. USA) equipped with flame-ionization detector (FID) and HP-5 capillary column $(30 \mathrm{~m} \times 0.32 \mathrm{~mm} \times 0.25 \mu \mathrm{m})$. Biodiesel yield will be quantified using tetradecane as the internal standard. The analysis of biodiesel for each sample will carried out by dissolving $1 \mathrm{~mL}$ of the sample into $5 \mathrm{~mL}$ of $\mathrm{n}$-hexane and injecting $0.5 \mu \mathrm{L}$ into GC. The yield of the biodiesel will be determined using the following equation:

$$
\text { Biodiesel yield }=\frac{w_{\text {tetradecane }} \times A_{B \times} f_{\text {tetradecane }}}{A_{\text {tetradecane }} \times w_{s}} \times 100 \%
$$

Where $\mathrm{w}_{\text {tetradecane }}$ is the weight of the internal standard, $A_{B}$ is the peak area of methyl esters, $f_{\text {tetradecane }}$ is the response factor, $A_{\text {tetradecane }}$ is the peak area of the internal standard, and $\mathrm{w}_{\mathrm{s}}$ is the weight of the sample.

\section{Experimental Design and Statistical Analysis}

A three-variable and five-level central composite design (CCD) will be adopted and used in this study.

\subsection{Characterization of the biodiesel}

The major properties of the biodiesel will be evaluated using recommended standard methods. The properties include; cetane number, flash point, water content, acid value oxidative stability, copper corrosion, kinematic 
viscosity and sulfur content will be determined. Other properties including pour point, cloud point, cold filter plugging point, density at $20^{\circ} \mathrm{C}$, ash content and glycerin content will be determined.

\section{The Research Work and Progress of the Overall Arrangements/Research Plan}

The research will take a year to acquire reagents; to synthesize four novel dicationic functional ionic liquids with an imidazolium structure for biodiesel production; to investigate the catalytic performance of transesterification of Allanblackia floribunda Seed oil with methanol to biodiesel to determine the effect of the optimization of reaction conditions on the transesterification using the response surface methodology (RSM) to evaluate the properties and application feasibility of the biodiesel obtained from Allanblackia floribunda Seed oil; and submission of report.

\section{Feasibility Analysis}

This study is unique of its kind and is intended to bring/ establish that Allanblackia floribunda Seed oil as one of the potential non-edible oils for biodiesel production

\section{Limitations}

Availability of high water usage concerning biogas production. High maintenance requirements will reduce the environmental benefits and increase carbon emissions and costs. Land use for Allanblackia floribunda tree will often compete with food crops, forest and urbanization. Food competition is ultimately the key social issue as energy crops will compete with food crops for valuable agricultural land. Taking waste wood from poor communities may remove self-sufficiency in areas where wood fuel is their only source of heat.

\section{Research Plan}

Chapter One: Introduction

i. Overview of Bio-energy

ii. Suitability vegetable for use as biodiesel.

Chapter Two: Biodiesel production from new-edible Allanblackia floribunda Seed oil.

Chapter Three: Acid treated attapulgite functionalized with Na compounds as novel bi-functional heterogenous solid catalysts for biodiesel production.

Chapter Four: Biodiesel production from waste non edible feedstock and Kinetics of the transesterification.

Chapter Five: Conclusion and Recommendation.

\section{Monitoring Procedures}

Performance figures, performance criteria and assessment aspects; biogas production biogas utilization environmental impacts socio-economic efficiency 


\section{Description of Biogas Production System}

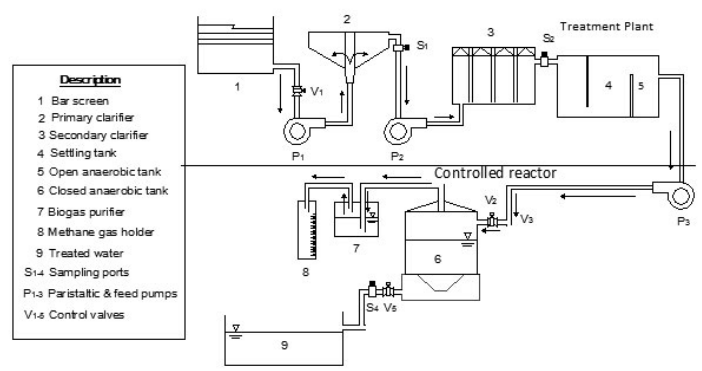

Figure 1: Biogas production system.

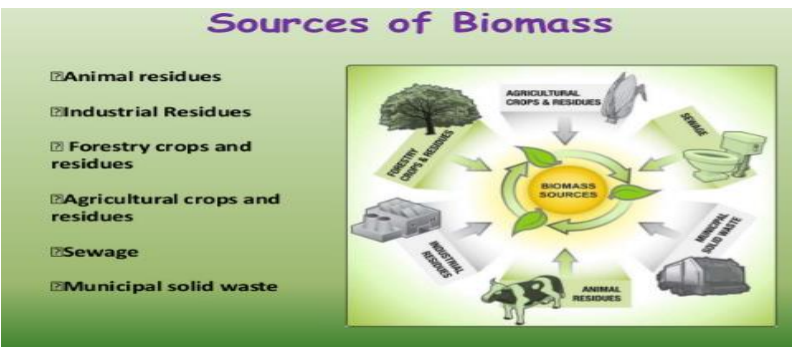

Figure 2: Sources of Biomass.

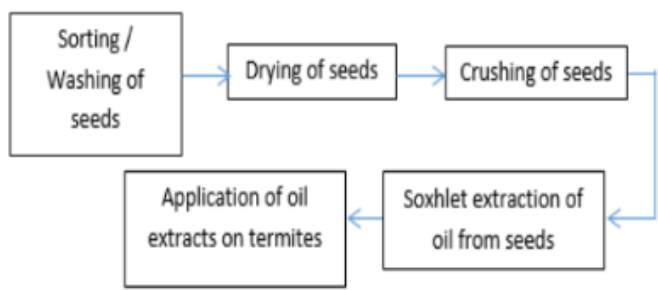

Figure 3: Flow chart for the extraction of oil from Allanblackia floribunda.

\section{Conclusion}

Biogas is yet to make significant impact in the energy sector in Ghana despite its potential for electricity, lighting (biogas lamps) and cooking in institutions, abattoirs and households. Biogas is a holistic approach to tackling energy crises in the twenty-first century. Professionals have proposed various ideas, plans, policies, and strategies and have implemented them in cities to achieve bioenergy goals. Government should play a role in promulgating supporting policies and strengthening the supervision and control of biogas projects. Emerging analysis is an appropriate method to evaluate the sustainability of alternative energy production, because it accounts for all inputs to the system. However, the generation of electricity does produce a product with higher energy quality and increased utility. Whether or not the conversion to electricity and the subsequent loss of sustainability is justified is a decision that needs to be made by the beneficiaries of the production system. 


\section{Benefits from the Research Findings}

Communities, People, local governments and Researchers.

\section{Resources Required}

Fund, Human resources, Research equipment, and Research facilities.

\section{Duration of the Research}

The research is made up of an experimental work and it will take four years for data collection and analyses to achieve a good work.

\section{References}

1. Singh SP, Singh D. Biodiesel production through the use of different sources and characterization of oils and their esters as the substitute of diesel: A review. Renew Sust Energ Rev 14 (2010): 200-216.

2. Bi Y, Ding D, Wang D. Low-melting-point biodiesel derived from corn oil via urea complexation. Bioresource Technol 101 (2010): 1220-1226.

3. Zabeti M, Daud WMAW, Aroua MK. Biodiesel production using alumina-supported calcium oxide: An optimization study. Fuel Process Technol 91 (2010): 243-248.

4. Lin L, Zhou CS, Saritporn V, et al. Opportunities and challenges for biodiesel fuel. Appl Energ 88 (2011): 1020-1031.

5. Mustafa B. Potential alternatives to edible oils for biodiesel production-A review of current work. Energ Convers Manage 52 (2011): 1479-1492.

6. Wu X, Leung DYC. Optimization of biodiesel production from camelina oil using orthogonal experiment. Appl Energ 88 (2011): 3615-3624.

7. Corro G, Tellez N, Ayala E, et al. Two-step biodiesel production from Jatropha curcas crude oil using SiO2·HF solid catalyst for FFA esterification step. Fuel 89 (2010): 2815-2821.

8. Nakpong P, Wootthikanokkhan S. Roselle (Hibiscus sabdariffa L.) oil as an alternative feedstock for biodiesel production in Thailand. Fuel 89 (2010): 1806-1811.

9. Kafuku G, Mbarawa M. Alkaline catalyzed biodiesel production from moringa oleifera oil with optimized production parameters. Appl Energ 87 (2010): 2561-2565.

10. Anwar F, Rashid U, Ashraf M, et al. Okra (Hibiscus esculentus) seed oil for biodiesel production. Appl Energ 87 (2010): 779-785.

11. Sharma YC, Singh B. An ideal feedstock, kusum (Schleichera triguga) for preparation of biodiesel: Optimization of parameters. Fuel 89 (2010): 1470-1474.

12. Wu JW, Lin LC, Tsai TH. Drug-drug interactions of silymarin on the perspective of pharmacokinetics. J Ethnopharmacol 121 (2009): 185-193. 
13. Doehmer J, Weiss G, McGregor GP, et al. Assessment of a dry extract from milk thistle (Silybum marianum) for interference with human liver cytochrome-P450 activities. Toxicol in Vitro 25 (2011): 2127.

14. Morazzoni P, Bombardelli E. Silybum marianum (Carduus marianus). Fitoterapia 46 (1995): 3-42.

15. Ghavami N, Ramin AA. Grain yield and active substances of milk thistle as affected by soil salinity. Soil Sci Plant Anal 39 (2008): 2608-2618.

16. Li F, Yang L, Zhao T, et al. Optimization of enzymatic pretreatment for n-hexane extraction of oil from Silybum marianum seeds using response surface methodology. Food Bioprod Process 90 (2012): 87-94.

17. Zhang J, Chen S, Yang R, et al. Biodiesel production from vegetable oil using heterogenous acid and alkali catalyst. Fuel 89 (2010): 2939-2944.

18. Suppalakpanya K, Ratanawilai SB, Tongurai C. Production of ethyl ester from crude palm oil by two-step reaction with a microwave system. Fuel 89 (2010): 2140-2144.

19. Ayhan D. Biodiesel from waste cooking oil via base-catalytic and supercritical methanol transesterification. Energ Convers Manage 50 (2009): 923-927.

20. Hayyan A, Alam MZ, Mirghani MES, et al. Reduction of high content of free fatty acid in sludge palm oil via acid catalyst for biodiesel production. Fuel Process Technol 92 (2011): 920-924.

21. Wang R, Zhou WW, Hanna MA, et al. Biodiesel preparation, optimization, and fuel properties from nonedible feedstock, Datura stramonium L. Fuel 91 (2012): 182-186.

22. Eevera T, Rajendran K, Saradha S. Biodiesel production process optimization and characterization to assess the suitability of the product for varied environmental conditions. Renew Energ 34 (2009): 762-765.

23. Rashid U, Anwar F. Production of biodiesel through optimized alkaline-catalyzed transesterification of rapeseed oil. Fuel 87 (2008): 265-273.

24. Martin RS, de la Cerda T, Uribe A, et al. Evaluation of guindilla oil (Guindilia trinervis Gillies ex Hook. et Arn.) for biodiesel production. Fuel 89 (2010): 3785-3790.

25. Agarwal AK, Rajamanoharan K. Experimental investigations of performance and emissions of Karanja oil and its blends in a single cylinder agricultural diesel engine. Appl Energ 86 (2009): 106-112.

26. Gerhard K. Biodiesel and renewable diesel: A comparison. Prog Energ Combust 36 (2010): 364-373.

27. Robert OD. Effect of antioxidants on the oxidative stability of methyl soyate (biodiesel). Fuel Process Technol 86 (2005): 1071-1085.

28. Sarin A, Singh NP, Sarin R, et al. Natural and synthetic antioxidants: Influence on the oxidative stability of biodiesel synthesized from non-edible oil. Energy 35 (2010): 4645-4648.

29. Rashid U, Anwar F, Knothe G. Biodiesel from Milo (Thespesia populnea L.) seed oil. Biomass Bioenerg 35 (2011): 4034-4039.

30. Bryan RM. Preparation of fatty acid methyl esters from hazelnut, high-oleic peanut and walnut oils and evaluation as biodiesel. Fuel 92 (2012): 231-238.

31. Ramos MJ, Fernandez CM, Casas A, et al. Influence of fatty acid composition of raw materials on biodiesel properties. Bioresource Technol 100 (2009): 261-268. 
32. Perez A, Casas A, Fernandez CM, et al. Winterization of peanut biodiesel to improve the cold flow properties. Bioresource Technol 101 (2010): 7375-7381.

33. Bhale PV, Deshpande NV, Thombre SB. Improving the low temperature properties of biodiesel fuel. Renew Energ 34 (2009): 794-800.

34. Thomas QC. Improving cold flow properties of canola-based biodiesel. Biomass Bioenerg 35 (2011): 600607.

Citation: Sylvia Adipah. Biodiesel Production from Allanblackia floribunda Seed oil. Journal of Environmental Science and Public Health 3 (2018): 104-112.

(C) 1 This article is an open access article distributed under the terms and conditions of the
Creative Commons Attribution (CC-BY) license 4.0 